\title{
Food, energy and macronutrient contribution of out-of-home foods in school-going adolescents in Cotonou, Benin
}

\author{
Eunice S. Nago ${ }^{1,2}$, Carl K. Lachat ${ }^{3}$, Lieven Huybregts ${ }^{2}$, Dominique Roberfroid ${ }^{3}$, Romain A. Dossa ${ }^{1}$ \\ and Patrick W. Kolsteren ${ }^{2,3} *$ \\ ${ }^{1}$ Department of Nutrition and Food Science, Faculty of Agricultural Sciences, University of Abomey-Calavi, 01 BP 526 Cotonou, \\ Benin \\ ${ }^{2}$ Department of Food Safety and Food Quality, Faculty of Bioscience Engineering, Ghent University, Coupure Links 653, \\ 9000 Ghent, Belgium \\ ${ }^{3}$ Nutrition and Child Health Unit, Department of Public Health, Prince Leopold Institute of Tropical Medicine, \\ Nationalestraat 155, Antwerp, Belgium
}

(Received 19 February 2009 - Revised 6 July 2009 - Accepted 21 July 2009 - First published online 12 October 2009)

The objective of the present study was to document the food, energy and macronutrient contribution of out-of-home prepared foods in school-going adolescents in Cotonou (Benin) and compare the food, energy and macronutrient intakes of low and high out-of-home consumers. We used a cross-sectional study with $24 \mathrm{~h}$ dietary recalls on two non-consecutive school days to collect food intake data. Low and high consumers were defined respectively as subjects whose percentage of daily energy intake from out-of-home foods was in the first and the third terciles of the sample distribution. The setting was twelve secondary schools in Cotonou with 656 adolescents aged 13-19 years. Out-of-home prepared foods contributed more than $40 \%$ of the daily energy, fat, protein, carbohydrate and fibre intakes and of the daily weight of food in the adolescents. They were highly present at breakfast and as afternoon snacks in high consumers, providing respectively 94 and $82 \%$ of the energy intake of high consumers at breakfast and as afternoon snacks. Low consumers ate more fruit and vegetables and cereal grain products than high consumers whereas high consumers consumed more sweet energy-dense foods. Both categories had a diet poor in fruit and vegetables (hardly one-fourth of the recommended $400 \mathrm{~g}$ ) and high in fat. We concluded that out-of-home foods are important in the diet of urban school adolescents in Benin. Therefore, they should be investigated in depth and taken into account in the development of interventions to promote healthy diet and lifestyles in adolescents.

Out-of-home foods: School-going adolescents: Urban Benin

Developing countries are becoming increasingly urbanised due to demographic growth and rural-urban migration ${ }^{(1)}$. This situation induces some dietary changes which are driving the epidemic of overweight, obesity and related chronic diseases $^{(2)}$. Low- and middle-income countries even seem to encounter these problems far more quickly compared with affluent countries ${ }^{(3)}$. The more sedentary lifestyles of urban dwellers are also responsible for this epidemic ${ }^{(2)}$. Recent studies in developing countries have shown a higher prevalence of overweight, obesity and associated chronic diseases in adults in urban areas than in rural areas ${ }^{(4-7)}$. In Benin, about $40 \%$ of individuals live in cities. Cotonou, the most populated city, shelters $25 \%$ of the urban population ${ }^{(8)}$. The overall prevalence of overweight and obesity among Beninese women aged 15-49 years is estimated to be $28 \%$ in urban areas, whereas in rural settings it is $13 \%$. In Cotonou, already $34 \%$ of women aged 15-49 years are overweight or obese ${ }^{(9)}$.

A remarkable dietary change which is pointed out when dealing with the increasing overweight and obesity rates in developing countries is the westernisation of the traditional diet which results in more fat and less fibre intake $^{(2)}$. In West Africa, another change is that diets are more based on ready-to-eat purchased foods with excessive amounts of saturated and trans-fatty acids, sugars and salt. In cities such as Bamako, Accra and Dakar, almost all individuals, regardless of age and socio-economic status, consume foods outside home in addition to home-prepared family meals ${ }^{(10)}$.

The impact of these dietary changes on the nutritional status of individuals from developing countries has been poorly assessed. There is a need for research to stop the progression of overweight, obesity and diet-related chronic diseases. In this context, adolescents should be a priority target since they are particularly prone to bad food choices and since adolescent obesity predicts adult obesity ${ }^{(11)}$. In Benin, urban adolescents are particularly exposed at school to outof-home prepared foods, such as canteen foods and street foods vended within school settings.

Abbreviation: DDS, dietary diversity score.

* Corresponding author: Professor Patrick W. Kolsteren, fax +32 324765 43, email pkolsteren@itg.be 
To date, there has been very little information on the importance of out-of-home prepared foods in the diet of the Beninese population. Moreover, this information is mainly about street foods and is restricted to sanitary conditions, income generation, characteristics of street food vendors and consumers and kinds of foods sold. No study has ever assessed the contribution of out-of-home prepared foods in general to the food and nutrient intakes of urban Beninese and of school-going adolescents specifically. The present study aims at generating some knowledge about the contribution of out-of-home prepared foods in the diet of urban schoolgoing adolescents in Benin. As there is no Beninese food composition table and as food composition tables from neighbouring countries do not give complete information about the micronutrient content of Beninese foods, the present study will focus only on energy and macronutrients. Thus, its objective is to document the food, energy and macronutrient contribution of out-of-home prepared foods in school-going adolescents in Cotonou on school days and compare the food, energy and macronutrient intakes of low and high consumers of out-of-home prepared foods.

\section{Methods}

\section{Sampling}

The present study was conducted in Cotonou (Benin). Students in Seconde, fifth grade of the seven at secondary school, were considered. Students at this level were aged at least 13 years and were expected to be able to answer survey questions properly. A maximum age level of 19 years was used as an additional criterion following the definition of adolescents by the WHO as those between the ages of 10 and 19 years. A minimum sample size of 570 students was calculated using an estimated percentage of the daily energy intake from out-of-home foods of $25 \%{ }^{(12)}$, a precision of $5 \%$, a $95 \%$ confidence level and a design effect of 2 to account for the clustering.

A list of all private ( $n$ 109) and public ( $n$ 18) secondary schools with level Seconde was obtained from the Beninese Ministry of Secondary Education. All schools that could be located in the city by means of any indication from the Ministry (phone number or address) were eligible for selection. Eligible schools were ninety-seven private and eighteen public schools. Then, $10 \%$ of each category were randomly selected: ten private and two public schools. All twelve schools were visited and authorisation from their directors was obtained. Information sessions were held in all Seconde classes and all students were invited to participate. The survey covered a final sample of 656 students who accepted and signed a written informed consent. This number corresponded to $87 \%$ of all Seconde students aged less than 19 years in the selected schools. A thirteenth school was selected additionally for pretesting.

\section{Data collection}

Nutritionists were recruited and trained for the whole data collection which took place in January to May 2007. The study language was French. Anthropometric measurements were done to assess the nutritional status of the sample.
Height and weight were measured twice following standard procedures $^{(13)}$. Girls were measured in a room by two women and boys in another room by two men. In each room, a booth was individually used for the measurements. For height, subjects were barefoot, without headdress and standing. They were measured to the nearest $0.1 \mathrm{~cm}$, using portable Seca 225 stadiometers (Seca, Hamburg, Germany). Weight was taken to the nearest $100 \mathrm{~g}$ with Seca 880 scales, with subjects standing and wearing underwear. BMI $\left(\mathrm{kg} / \mathrm{m}^{2}\right)$, which is the weight $(\mathrm{kg})$ divided by the squared height $\left(\mathrm{m}^{2}\right)$ was calculated. It was used as the index of thinness, normal status, overweight and obesity with the sex- and age-specific cut-offs of the International Obesity Task Force ${ }^{(14,15)}$.

Waist circumference was also measured. It has been found to be a simple and effective measure of truncal adiposity in adolescents ${ }^{(16,17)}$. It was measured twice with Seca 200 tape measures (Seca, Hamburg, Germany), at the navel in boys and halfway between the bottom of the ribs and the top of the hip bone in girls. The sex- and age-specific cut-offs of Taylor et al. (17) were used for waist circumference. For each anthropometric characteristic (height, weight or waist circumference), the average of the two measurements was taken. Subjects' age was determined from their date of birth in school register-books and the day of measurement.

\section{Dietary assessment}

The place of preparation was used as the criterion to define out-of-home foods. Foods considered as 'out-of-home foods' were foods not prepared or processed at home, as opposed to home-prepared foods. The following were considered 'out-of-home foods': 'street foods' as defined by the $\mathrm{FAO}^{(18)}$ as ready-to-eat foods and beverages prepared and/or sold by vendors and hawkers especially in streets and other similar public places (this includes foods sold within and around the schools which are not from school canteens or restaurants); foods from formal restaurants and school canteens and commercial industrial products.

The food consumption of the subjects was assessed by a $24 \mathrm{~h}$ dietary recall repeated on two non-consecutive school days. These two days were chosen among Tuesday, Wednesday and Friday, taking into account the curriculum of the students. Monday and Thursday were not eligible for selection because the first is preceded by a weekend day and the second is preceded by a Wednesday, which is a half school day where students have only morning classes. We wanted the food intake to be representative of full school days (with morning and afternoon classes). The average for the two recall days was used to estimate food intake.

The procedure used for the $24 \mathrm{~h}$ recalls was adapted from Gibson and Ferguson's manual for developing countries ${ }^{(19)}$. The following consecutive steps were used to estimate food consumption: listing of foods consumed by the adolescent in the previous $24 \mathrm{~h}$, including drinks except water; collection of information on the time when each food was eaten; detailed description of each food, the amount eaten and the place of preparation; final checking to recall forgotten foods. Standardised recipes and portion sizes were used for street foods. For each street food, all the vendors who were selling it around and inside all the schools were interviewed. The vendors provided information about the recipe and estimated 
the amount of ingredients with common household utensils (six bowls, two plates, four spoons and one cup) that each interviewer was carrying; this was to reduce lapse of memory. Later, the ingredients were purchased and weighed in the same utensils to the nearest $1 \mathrm{~g}$ using Beurer DS 80 digital diet scales (Beurer, Ulm, Germany). Portions of street foods were purchased, measured and recorded with the equivalent price. Each measure of ingredients and portions from each vendor was taken thrice and the average weight was considered. For each recipe, two to six recipes were collected and the average used as the standardised recipe. During the recalls, students were asked to give the price of the street foods they consumed as an indication of the weight.

For foods prepared at home, estimation of portions eaten and amounts of ingredients was based on the common household utensils which interviewers had with them during the recalls. The equivalent weights were determined later by weighing ingredients and portions of meals cooked according to the average recipes collected from the subjects. Meals were cooked by two women recruited for this purpose. For fish, meat, egg and local cheese eaten at home, subjects gave the equivalent price as if these items had been street foods and the equivalent weight was used.

Only one school had a canteen. Recipes of foods from this canteen were obtained by two interviewers by direct observation; ingredients and portions served were weighed by them. Very few foods came from restaurants. Their price was asked during the recalls and equivalent portions were purchased and weighed. Recipes for home foods were used for restaurant foods, as it was difficult to get recipes from the restaurants. The food recall procedure was pilot tested in fifteen students in a thirteenth school selected for this purpose.

Before the food intake survey, we defined daily meal moments from interviews with students. Most subjects reported having their first meal at school shortly before 08.00 hours when courses start or during the morning break at 09.45 hours before they return to class; they considered this first meal as their breakfast. Lunch was between 12.00 hours when they leave school and 15.00 hours when they start afternoon classes. Dinner was mainly reported between 20.00 and 22.00 hours. Thus, meals were defined as follows: (1) breakfast from 06.00 am to 11.59 hours; (2) lunch from 12.00 to 14.59 hours; (3) afternoon snack from 15.00 to 19.59 hours; (4) dinner from 20.00 to 21.59 hours; (5) night snack from 22.00 to 05:59 hours.

In absence of a Beninese food composition table, nutrient intake was estimated from three food composition tables used in Africa ${ }^{(20-22)}$ : the Malian food composition table for $51 \%$ of foods $^{(20)}$, the East African table for $22 \%{ }^{(21)}$ and the FAO table for $14 \%^{(22)}$. Nutrition information on food packages was used for some manufactured products $(2 \%$ of foods). Chemical analysis data from the Faculty of Agricultural Sciences of the University of Abomey-Calavi in Benin $^{(23)}$ were used for $8 \%$ of foods and the online Belgian food composition database (www.internubel.be) for $3 \%$.

The dietary diversity score (DDS) was calculated to appreciate the dietary diversity of the adolescents' diet. This score refers to the number of different food groups consumed, irrespective of frequency and amount eaten. It has been shown to adequately predict dietary quality ${ }^{(24)}$. Twelve food groups were adapted from the ones used in the FAO food composition table for use in Africa ${ }^{(22)}$ : (1) cereals and cereal products; (2) starchy roots, tubers, fruit and their products; (3) grain legumes and legume products; (4) nuts, seeds and their products; (5) fruit, vegetables and vegetable products; (6) meat and meat products; (7) fish, shellfish and their products; (8) eggs, milk and milk products; (9) oils and fats; (10) sweet foods (including sugars and syrups, sweet beverages, candies, chocolate, lollipops); (11) other beverages; (12) miscellaneous (such as condiments and coffee). Bananas and potatoes were included in the 'starchy roots, tubers, fruit and their products' group because we considered them as starchy and energy-dense items. The DDS was calculated with ten food groups, excluding sweet and miscellaneous foods. Sweet foods were not included because they were considered as energy-dense and nutrient-poor foods which impede health ${ }^{(25,26)}$. Miscellaneous foods were considered as superfluous items used in small amounts and were also excluded.

\section{Statistical analysis}

Anthropometric data entry was done in Microsoft Excel version 2003 (Microsoft Corporation, Seattle, WA, USA). Food intake data were processed using a format designed in Microsoft Access version 2003 (Microsoft Corporation, Redmond, WA, USA). Statistical analyses were performed with the Stata software package (version 10.0, Intercooled Stata; StataCorp LP, College Station, TX, USA). The mean percentage of daily energy intake provided by out-of-home foods was separated in terciles and three groups were identified: low ( $<34 \%$ of energy from out-of-home foods), average $(\geq 34 \%$ and $<55 \%)$ and high $(\geq 55 \%)$ consumers of out-of-home foods. Low and high consumers were compared for age, anthropometric characteristics and food and nutrient intakes. Data were analysed using survey procedures in Stata and differences between groups were tested by regression analysis adjusted for clustering of schools. All tests were two-sided and a significance level of $5 \%$ was used for all analyses.

Under-reporters and over-reporters were not excluded from data analysis since the accuracy of current equations in predicting BMR of adolescents is still controversial ${ }^{(27,28)}$. Several factors, such as ethnicity, have been shown to influence the estimation of BMR by current predictive equations. Particularly, the appropriateness of the equations of FAO, WHO and United Nations University ${ }^{(29)}$ for use in our sample was questioned since these equations tend to overestimate BMR or RMR in children or adolescents from different populations ${ }^{(27,28)}$. We also ran a data analysis after excluding under-reporters and over-reporters identified respectively as having a daily energy intake inferior to $1.2 \mathrm{BMR}$ and superior to $2.4 \mathrm{BMR}$. A value of 1.2 for the physical activity level has been suggested as a minimum corresponding to "chair-bound or bed-bound' individuals (survival limit) and a physical activity level of 2.4 as the maximum for a sustainable lifestyle ${ }^{(30)}$. We calculated BMR from height and weight using the sex- and age-specific equations of FAO, WHO and United Nations University ${ }^{(29)}$.

The present study was conducted according to the guidelines laid down in the Declaration of Helsinki and all procedures involving human subjects were approved by the 
Direction of Health Research of the Beninese Ministry of Public Health. Written informed consent was obtained from all subjects and school directors.

\section{Results}

A total of 656 adolescents were sampled and data from 553 adolescents ( $73 \%$ of all Seconde students aged less than 19 years in the selected schools) were analysed. Seventeen students (six males, eleven females) with missing data for age or anthropometric measures and eighty-six students (sixty-two males, twenty-four females) with incomplete food intake data were excluded. From the remaining 553 adolescents, $61 \%$ were males.

\section{Age and anthropometric characteristics of the sample}

Table 1 presents age and anthropometric characteristics of the low, average and high consumers of out-of-home foods. In total, there were $8.3 \%$ overweight and $4.0 \%$ obese individuals in the sample. The prevalence of truncal adiposity in the sample was $8.0 \%$. There was no significant difference between low and high consumers of out-of-home prepared foods in prevalence of overweight, obesity and truncal adiposity (Table 2).

\section{Daily contribution of out-of-home foods}

On average, out-of-home foods contributed $40 \%$ or more of the daily energy, fat, protein, carbohydrate, fibre and total food intakes of the whole sample (Table 3). Street foods were predominant among out-of-home foods. They contributed more than $86 \%$ of food, energy and macronutrients from out-of-home foods and up to $94 \%$ of the fibre content of out-of-home foods.

In the sample, breakfast, lunch and dinner accounted for 22,28 and $23 \%$ of the daily energy intake, respectively. Afternoon snacks provided $20 \%$ of the daily energy intake and night snacks, $7 \%$. When we considered the whole sample, we noticed that out-of-home foods were particularly present at breakfast and as afternoon snacks (Table 4) and that other meals consisted mostly of home-prepared foods. When categories of out-of-home consumers were considered separately, the energy contribution of out-of-home foods was particularly high in high consumers at breakfast and in afternoon snacks and very low in low consumers for lunch, dinner and night snacks.
Daily intakes of low and high consumers of out-of-home foods

Mean daily food, energy and macronutrient intakes of low and high consumers of out-of-home foods were not significantly different (Table 5). The percentage energy from fat was the same for the two groups but the percentage energy from protein was significantly higher in low consumers compared with high consumers.

\section{Dietary diversity and weight contribution of food groups in low and high consumers}

The DDS of low and high out-of-home consumers were equal to 7 (SD 1) food groups. This is three-quarters of all food groups defined to compile DDS. In the two categories of consumers, 'cereals and cereal products' and 'sweet foods' were the most consumed food groups (Table 6). Low consumers ate significantly more cereals and cereal products than high consumers. Mean intake of sweet foods was $246 \mathrm{~g}$ higher in high consumers and this difference was significant. When the whole sample was considered, out-of-home foods provided $84 \%$ of all sweet foods consumed daily v. $16 \%$ for home-prepared foods $(P<0 \cdot 001)$.

Common items in the cereal group were wheat bread, maize-based dough and porridges, rice and pasta. Sweet foods consisted of energy-dense foods such as sweet beverages, candies, chocolate and lollipops. 'Starchy roots, tubers, fruit and their products' were also predominant in low consumers as well as in high consumers but were more consumed by low consumers. Major items in this food group were yam or cassava-based dough, boiled or fried yam, cassava, potatoes, sweet potatoes and bananas (fried or not).

Total intake of fruit and vegetables was significantly higher in low out-of-home consumers. When the whole sample was considered, out-of-home foods accounted for only $26 \%$ of daily fruit and vegetables $v .74 \%$ in home-prepared foods $(P<0.001)$. Pineapples, mangoes, apples and oranges were present as fruit. Major vegetables were green leafy vegetables consumed in sauces. When animal sources of protein were considered, 'eggs, milk and milk products' were significantly more consumed by high consumers.

\section{Excluding or including under-reporters and over-reporters}

A large number of subjects were classified as under-reporters (121 subjects) and thirteen as over-reporters.

Table 1. Age and anthropometric characteristics by category of out-of-home consumers (Mean values and standard deviations)

\begin{tabular}{|c|c|c|c|c|c|c|c|c|c|}
\hline & \multicolumn{2}{|c|}{ All (n 553) } & \multicolumn{2}{|c|}{ Low ( $n$ 184) } & \multicolumn{2}{|c|}{ Average ( $n$ 185) } & \multicolumn{2}{|c|}{ High ( $n$ 184) } & \multirow[b]{2}{*}{$P^{*}$} \\
\hline & Mean & SD & Mean & SD & Mean & SD & Mean & SD & \\
\hline Age (years) & $16 \cdot 3$ & 1.3 & $16 \cdot 5$ & $1 \cdot 3$ & $16 \cdot 2$ & $1 \cdot 2$ & $16 \cdot 1$ & $1 \cdot 3$ & 0.067 \\
\hline Weight (kg) & $57 \cdot 3$ & $11 \cdot 3$ & $57 \cdot 3$ & $10 \cdot 7$ & $56 \cdot 3$ & $10 \cdot 1$ & 58.3 & $12 \cdot 9$ & 0.491 \\
\hline Height $(m)$ & 1.7 & 0.1 & 1.7 & 0.1 & 1.6 & 0.1 & 1.7 & 0.1 & 0.258 \\
\hline Waist circumference $(\mathrm{cm})$ & 70.5 & $7 \cdot 3$ & $70 \cdot 3$ & $6 \cdot 8$ & $70 \cdot 1$ & $6 \cdot 8$ & $71 \cdot 0$ & $8 \cdot 1$ & 0.206 \\
\hline BMI $\left(\mathrm{kg} / \mathrm{m}^{2}\right)$ & 20.9 & $3 \cdot 7$ & $20 \cdot 7$ & $3 \cdot 7$ & 20.7 & 3.3 & $21 \cdot 2$ & 4.1 & 0.262 \\
\hline
\end{tabular}

Low, $<34 \%$ of energy from out-of-home foods; average, $\geq 34 \%$ and $<55 \%$ of energy from out-of-home foods; high, $\geq 55 \%$ of energy from out-of-home foods. ${ }^{*}$ Comparison between low and high out-of-home consumers using regression analysis adjusted for clustering of schools. 
Table 2. Nutritional status classes of the sample by category of out-of-home consumers

(Number of subjects and percentages)

\begin{tabular}{|c|c|c|c|c|c|c|c|c|c|}
\hline & \multicolumn{2}{|c|}{ All $(n 553)$} & \multicolumn{2}{|c|}{ Low $(n 184)$} & \multicolumn{2}{|c|}{ Average ( $n 185)$} & \multicolumn{2}{|c|}{ High ( $n$ 184) } & \multirow[b]{2}{*}{$P^{\star}$} \\
\hline & $n$ & $\%$ & $n$ & $\%$ & $n$ & $\%$ & $n$ & $\%$ & \\
\hline Thinness $†$ & 74 & $13 \cdot 4$ & 28 & $15 \cdot 2$ & 23 & $12 \cdot 4$ & 23 & $12 \cdot 5$ & 0.773 \\
\hline Normal status $\dagger$ & 411 & 74.3 & 135 & 73.4 & 143 & $77 \cdot 3$ & 133 & $72 \cdot 3$ & 0.463 \\
\hline Overweight† & 46 & $8 \cdot 3$ & 16 & 8.7 & 15 & $8 \cdot 1$ & 15 & $8 \cdot 1$ & 0.933 \\
\hline Obesity & 22 & $4 \cdot 0$ & 5 & $2 \cdot 7$ & 4 & $2 \cdot 1$ & 13 & $7 \cdot 1$ & 0.193 \\
\hline Normal waist circumference $\ddagger$ & 509 & $92 \cdot 0$ & 171 & 92.9 & 174 & 94.0 & 164 & 89.1 & 0.141 \\
\hline Truncal adiposity $\ddagger$ & 44 & $8 \cdot 0$ & 13 & $7 \cdot 1$ & 11 & 5.9 & 20 & $10 \cdot 9$ & 0.141 \\
\hline
\end{tabular}

Low, $<34 \%$ of energy from out-of-home foods; average, $\geq 34 \%$ and $<55 \%$ of energy from out-of-home foods; high, $\geq 55 \%$ of energy from out-of-home foods.

${ }^{*}$ Comparison between low and high out-of-home consumers using regression analysis adjusted for clustering of schools.

$\dagger$ The sex- and age-specific cut-offs of the International Obesity Task Force ${ }^{(14,15)}$ for children and adolescents were used.

$\ddagger$ The sex- and age-specific cut-offs of Taylor et al. ${ }^{(17)}$ for children and adolescents were used.

Excluding under-reporters and over-reporters in the analysis increased the mean daily energy intake from $10033 \mathrm{~kJ}$ to $10870 \mathrm{~kJ}$ but did not alter major conclusions of the present study or affect the differences between low and high consumers of out-of-home foods. The contribution of out-of-home foods to the daily food, energy, protein, fat, carbohydrate and fibre intakes remained $40 \%$ or more. There was still no significant difference between the daily food, energy and macronutrient intakes of low and high consumers of out-ofhome foods. The percentage energy from fat was the same for the two groups and was high. The fruit and vegetable intake and the amount of cereals and cereal products remained higher in low consumers. The amount of sweet foods remained higher in high consumers. There was still no difference in the prevalence of overweight, obesity and truncal adiposity between low and high consumers.

\section{Discussion}

The contribution of out-of-home foods in the daily diet of the adolescents on school days was substantial. They provided $40 \%$ or more of the daily weight of food consumed and of energy, protein, fat, carbohydrate and fibre intakes. They were mainly consumed at breakfast and as afternoon snacks. Street foods constituted the greatest part of out-of-home foods consumed by the adolescents, supplying more than $86 \%$ of food, energy and macronutrients from out-of-home foods.

Compared with the diet of low consumers of out-of-home foods, the diet of high consumers revealed a similar dietary diversity. Both categories consumed seven out of the ten food groups defined in the present study to compile DDS. Low consumers ate more fruit and vegetables; however, both categories consumed few fruit and vegetables, only one-quarter of the recommended $400 \mathrm{~g}^{(26,31)}$. High consumers ate far more sweet foods, fewer 'cereals and cereal products', fewer 'starchy roots, tubers, fruit and their products' than low consumers. Low and high consumers had a high fat intake, with $30 \%$ energy from fat, already the maximum level recommended by WHO/FAO to prevent chronic diseases ${ }^{(26)}$. But globally, low and high consumers of out-of-home foods had a similar daily food, energy and macronutrient intake. This may be the reason why no difference in nutritional status between the two categories was detected either.

There is very little information about the food and nutrient contribution of foods prepared out of home in adolescents and on the diet of adolescents in general. In addition, the very few studies that have been done did not use the same definition for out-of-home foods, which makes a comparison between studies difficult. Some studies used the place of preparation as we $\operatorname{did}^{(25,32)}$ but others used different definitions ${ }^{(33,34)}$ such as the definition based on the place of consumption and considering out-of-home foods as foods consumed outside the home ${ }^{(34)}$. We considered the place of preparation the best criterion to use since the quality of foods and the implications for health depend more on where (and by whom) they are cooked than on the place of consumption. A review of existing studies would be needed to determine the best definition to be used as an international standard for out-of-home foods.

In a study in Nairobi ${ }^{(32)}$, medians of 13.4 and $22.4 \%$ as percentages of energy from non-home-prepared foods were found

Table 3. Daily food, energy and macronutrient intakes from home-prepared and out-of-home foods (Mean values and standard deviations and percentages of total intakes)

\begin{tabular}{|c|c|c|c|c|c|c|c|}
\hline & \multicolumn{3}{|c|}{ Home-prepared } & \multicolumn{3}{|c|}{ Out-of-home } & \multirow[b]{2}{*}{$P^{*}$} \\
\hline & Mean & SD & $\%$ & Mean & SD & $\%$ & \\
\hline Energy (kJ) & 5447 & 2574 & 55 & 4586 & 2618 & 45 & 0.283 \\
\hline Fat $(\mathrm{g})$ & 46 & 26 & 57 & 35 & 23 & 43 & 0.064 \\
\hline Protein (g) & 39 & 21 & 60 & 25 & 18 & 40 & $<0.001$ \\
\hline Carbohydrate (g) & 188 & 100 & 52 & 172 & 99 & 48 & 0.683 \\
\hline Fibre (g) & 11 & 12 & 55 & 7 & 7 & 45 & 0.215 \\
\hline Weight (g)† & 1018 & 499 & 59 & 720 & 490 & 41 & 0.689 \\
\hline
\end{tabular}

${ }^{*}$ Comparison of absolute intakes between home-prepared and out-of-home foods using regression analysis adjusted for clustering of schools.

† Weight of food for each place of preparation. 
Table 4. Energy intake $(\mathrm{kJ})$ of the sample and energy contribution of out-of-home foods (\%) per meal moment (Mean values and standard deviations)

\begin{tabular}{|c|c|c|c|c|c|c|c|c|c|c|c|c|}
\hline & \multicolumn{3}{|c|}{ All $(n 553)$} & \multicolumn{3}{|c|}{ Low $(n 184)$} & \multicolumn{3}{|c|}{ Average ( $n$ 185) } & \multicolumn{3}{|c|}{ High ( $n$ 184) } \\
\hline & Mean & SD & Out (\%) & Mean & SD & Out (\%) & Mean & SD & Out (\%) & Mean & SD & Out (\%) \\
\hline Breakfast & 2152 & 1356 & 86 & 1495 & 1289 & 74 & 2310 & 1267 & 87 & 2650 & 1242 & 94 \\
\hline Lunch & 2819 & 1375 & 36 & 3044 & 1395 & 7 & 2709 & 1269 & 28 & 2704 & 1427 & 66 \\
\hline Afternoon snacks & 2028 & 1479 & 67 & 1626 & 1423 & 50 & 2089 & 1427 & 64 & 2367 & 1492 & 82 \\
\hline Dinner & 2321 & 1556 & 18 & 2657 & 1622 & 5 & 2463 & 1621 & 20 & 1843 & 1279 & 25 \\
\hline Night snacks & 713 & 1110 & 27 & 855 & 1313 & 10 & 710 & 1039 & 28 & 575 & 922 & 41 \\
\hline
\end{tabular}

Low, $<34 \%$ of energy from out-of-home foods; average, $\geq 34 \%$ and $<55 \%$ of energy from out-of-home foods; high, $\geq 55 \%$ of energy from out-of-home foods; Out, percentage energy contribution of out-of-home foods per meal moment.

for consumers aged 9-14 years, respectively, in Korogocho and Dandora, two low-income areas. In this study in Nairobi, consumers were defined as subjects in the three upper quartiles of the proportion of daily energy consumed as out-of-home prepared foods. We obtained a median energy contribution from out-of-home prepared foods of $52 \%$ in the present study using the same classification of consumers. The big difference with the study in Nairobi could be explained by the fact that subjects in the study in Nairobi were selected in two low-income areas where some individuals had no regular income and others a very low income. Therefore, children may have had no or little pocket money to buy out-of-home foods. In Dandora, where the higher figure $(22.4 \%)$ was found, individuals had a more regular and higher income than in Korogocho. A difference between weekdays and weekends could also explain this difference since the present study included no weekend day contrary to the study in Nairobi. During weekends, children probably had less access to out-of-home foods than on weekdays when they go to school. Also, subjects from Nairobi were younger than our subjects, which could be an additional explanation.

Although in the present study there was no difference in overall energy and macronutrient intake between low and high consumers, out-of-home foods were shown to contain more sweet energy-dense foods than home-prepared foods. Diets rich in sweet foods are energy-dense but nutrient-poor and usually have a low content of vitamins and minerals ${ }^{(25)}$. Consequently, a high consumption of out-of-home foods by the adolescents may cause adverse health outcomes later and, in particular, may induce weight gain in high consumers since energy-dense foods are linked to the global obesity epidemic $^{(26)}$. In this context, reducing the added sugars in adolescents' diets by replacing sweet foods with fresh fruit and vegetables may decrease the energy density and increase the micronutrient density of their diets. Therefore, it would be a good strategy for the prevention of overweight, obesity and related chronic diseases. Studies performed in Western countries show that providing free fruit and vegetables to students is a good way to increase their fruit and vegetable intake over years ${ }^{(35-37)}$.

The issue of 'empty calories', a term used to describe foods high in energy but low in micronutrients, would be interesting to study in the context of out-of-home foods but this would necessitate having food composition data for key micronutrients $^{(38)}$. Such information is currently not available for Benin. This information could also be used for a further investigation of the dietary quality of out-of-home foods. More complex and precise indices of dietary quality than the DDS, including the appreciation of the intake of key micronutrients, could be used. As the DDS has been shown to adequately predict micronutrient adequacy $^{(24)}$ and even nutritional status ${ }^{(38)}$, the relatively high DDS in the adolescents suggests a good micronutrient adequacy of their diet at present. This needs to be assessed in depth.

Low and high out-of-home consumers had a similar carbohydrate intake. High consumers, however, ate more sweet foods compared with low consumers. Interestingly, they consumed fewer cereals and cereal products and fewer starchy roots, tubers, fruit and their products. These findings suggest a partial substitution of sources of complex carbohydrates for sources of simple carbohydrates when eating substantially out-of-home foods.

Table 5. Total daily food, energy and macronutrient intakes by category of out-of-home consumers (Mean values and standard deviations)

\begin{tabular}{|c|c|c|c|c|c|c|c|c|c|}
\hline & \multicolumn{2}{|c|}{ All (n 553) } & \multicolumn{2}{|c|}{ Low $(n 184)$} & \multicolumn{2}{|c|}{ Average ( $n$ 185) } & \multicolumn{2}{|c|}{ High ( $n$ 184) } & \multirow[b]{2}{*}{$P^{\star}$} \\
\hline & Mean & SD & Mean & SD & Mean & SD & Mean & SD & \\
\hline Energy (kJ) & 10033 & 2833 & 9678 & 2841 & 10281 & 2710 & 10139 & 2911 & 0.284 \\
\hline Fat $(\mathrm{g})$ & 82 & 29 & 78 & 31 & 86 & 27 & 81 & 28 & 0.534 \\
\hline Protein $(g)$ & 64 & 24 & 64 & 24 & 66 & 23 & 63 & 25 & 0.656 \\
\hline Carbohydrate (g) & 360 & 112 & 349 & 113 & 364 & 112 & 367 & 110 & 0.339 \\
\hline Fibre (g) & 18 & 14 & 20 & 16 & 19 & 14 & 15 & 10 & 0.049 \\
\hline Weight of food (g) & 1738 & 566 & 1712 & 569 & 1772 & 532 & 1732 & 591 & 0.848 \\
\hline Energy from fat (\%) & 31 & 7 & 30 & 7 & 32 & 6 & 30 & 6 & 0.833 \\
\hline Energy from protein (\%) & 11 & 3 & 11 & 3 & 11 & 3 & 10 & 3 & 0.016 \\
\hline
\end{tabular}

Low, $<34 \%$ of energy from out-of-home foods; average, $\geq 34 \%$ and $<55 \%$ of energy from out-of-home foods; high, $\geq 55 \%$ of energy from out-of-home foods

${ }^{\star}$ Comparison between low and high out-of-home consumers using regression analysis adjusted for clustering of schools. 
Table 6. Total daily consumption of food groups by category of out-of-home consumers $(\mathrm{g})$ (Mean values and percentages)

\begin{tabular}{|c|c|c|c|c|c|c|c|c|c|}
\hline & \multicolumn{2}{|c|}{ All $(n 553)$} & \multicolumn{2}{|c|}{ Low $(n 184)$} & \multicolumn{2}{|c|}{$\begin{array}{c}\text { Average } \\
(n 185)\end{array}$} & \multicolumn{2}{|c|}{ High ( $n$ 184) } & \multirow[b]{2}{*}{$P^{*}$} \\
\hline & Mean & $\% \dagger$ & Mean & $\% \dagger$ & Mean & $\% †$ & Mean & $\% \dagger$ & \\
\hline Cereals and cereal products & 734 & 42 & 795 & 46 & 768 & 43 & 641 & 37 & 0.001 \\
\hline Starchy roots, tubers, fruit and their products & 174 & 10 & 187 & 11 & 169 & 10 & 167 & 10 & 0.042 \\
\hline Grain legumes and legume products & 42 & 2 & 54 & 3 & 38 & 2 & 34 & 2 & 0.164 \\
\hline Nuts, seeds and their products & 7 & 0 & 8 & 1 & 6 & 0 & 6 & 0 & 0.121 \\
\hline Fruit, vegetables and vegetable products & 97 & 6 & 107 & 6 & 103 & 6 & 80 & 5 & 0.019 \\
\hline Meat and meat products & 53 & 3 & 48 & 3 & 55 & 3 & 56 & 3 & 0.605 \\
\hline Fish, shellfish and their products & 44 & 3 & 49 & 3 & 48 & 3 & 35 & 2 & 0.074 \\
\hline Eggs, milk and milk products & 60 & 4 & 36 & 2 & 67 & 4 & 77 & 4 & $<0.001$ \\
\hline Oils and fats & 39 & 2 & 37 & 2 & 39 & 2 & 41 & 2 & 0.131 \\
\hline Other beverages & 176 & 10 & 189 & 11 & 193 & 11 & 147 & 9 & 0.004 \\
\hline Sweet foods $\ddagger$ & 304 & 18 & 194 & 11 & 278 & 16 & 440 & 25 & 0.003 \\
\hline Miscellaneous§ & 8 & 0 & 8 & 1 & 8 & 0 & 8 & 1 & 0.944 \\
\hline Total & 1738 & 100 & 1712 & 100 & 1772 & 100 & 1732 & 100 & 0.848 \\
\hline
\end{tabular}

Low, $<34 \%$ of energy from out-of-home foods; average, $\geq 34 \%$ and $<55 \%$ of energy from out-of-home foods; high, $\geq 55 \%$ of energy from out-of-home foods.

${ }^{*}$ Comparison between low and high out-of-home consumers using regression analysis adjusted for clustering of schools.

† Percentage of the total daily weight of food consumed.

$\ddagger$ Sweet foods are energy-dense foods such as sweet beverages, candies and chocolate.

$\S$ Miscellaneous are foods used in small quantities such as condiments and coffee.

The fact that under-reporters and over-reporters were not excluded from data analysis in the present study could constitute a limitation. However, excluding them did not alter the major conclusions of the present study or affect the differences between low and high consumers of out-of-home foods. The present study sheds light on the food, energy, fat, protein, carbohydrate and fibre intakes and the contribution of outof-home foods in a large number of school-going adolescents of a large age range (13-19 years) in Cotonou, the most urbanised area in Benin. To our knowledge, it is the first study of this type in Benin. The present results suggest outof-home foods as a great nutritional concern in urban school adolescents in Benin. Therefore, they should be taken into account in the development of adapted interventions to promote healthy diet and lifestyles in these adolescents.

The lack of fruit and vegetables, the high intake of sweet foods and the high percentage of energy from fat in the adolescents' diet are conducive to an increase in the prevalence of overweight and obesity in the subjects (already $12.3 \%$ ) and consequently to diet-related chronic diseases. Our findings call for more in-depth studies on the nutritional contribution and dietary quality of out-of-home foods in particular and of the overall diet of school adolescents in order to develop well-adapted preventive interventions. Schools constitute a good channel to reach most urban adolescents and are considered to be good settings for effective nutrition interventions in adolescents ${ }^{(39,40)}$. The possibility to develop and implement school-based fruit and vegetable interventions in adolescents in Benin should be investigated. The effectiveness of these interventions in replacing sweet foods by fruit and vegetables and reducing dietary fat and energy in these adolescents should also be addressed.

\section{Acknowledgements}

The authors wish to thank all the students and school staff for their cooperation during the data collection. The present study was supported by Nutrition Third World, a Belgian non-profit organisation and by The Belgian Development Cooperation.

E. S. N. collected the data and drafted the manuscript. C. K. L., R. A. D. and P. W. K. assisted with the study design. C. K. L., L. H., D. R. and P. W. K. contributed to data analysis. All authors participated in the writing of the article.

None of the authors declares a conflict of interest.

\section{References}

1. UN Population Division (2002) World urbanization prospects: the 2001 revision. http://www.un.org/esa/population/ publications/wup2001/WUP2001_CH1.pdf

2. Popkin BM (2001) The nutrition transition and obesity in the developing world. J Nutr Suppl. 10, 871S-873S.

3. Popkin BM (2002) Part II. What is unique about the experience in lower- and middle-income less industrialised countries compared with the very-high-income industrialised countries? Public Health Nutr 5, 205-214.

4. Abubakari AR, Lauder W, Agyemang C, et al. (2008) Prevalence and time trends in obesity among adult West African populations: a meta-analysis. Obes Rev 9, 297-311.

5. Pérez-Cueto A \& Kolsteren P (2004) Changes in the nutritional status of Bolivian women 1994-1998: demographic and social predictors. Eur J Clin Nutr 58, 660-666.

6. Tuan NT, Tuong PD \& Popkin BM (2008) Body mass index (BMI) dynamics in Vietnam. Eur J Clin Nutr 62, 78-86.

7. Ntandou G, Delisle H, Agueh V, et al. (2008) Physical activity and socioeconomic status explain rural-urban differences in obesity: a cross-sectional study in Benin (West Africa). Ecol Food Nutr 47, 313-337.

8. Republic of Benin National Institute of Statistics and Economic Analysis (INSAE) (2003) Troisième Recensement Général de la Population et de L'habitation, Février 2002, Principaux Indicateurs Sociodémographiques (Third General Population Census, February 2002: Major Socio-demographic Indicators). Cotonou: Institut National de la Statistique et de l'Analyse Economique. 
9. Republic of Benin National Institute of Statistics and Economic Analysis (INSAE) (2002) Enquête Démographique et de Santé au Bénin 2001 (Demographic and Health Survey in Benin in 2001). Cotonou: Institut National de la Statistique et de l'Analyse Economique.

10. Lopriore C \& Muehlhoff E (2003) Food security and nutrition trends in West Africa - Challenges and the way forward. In Food Based Approaches for a Healthy Nutrition in West Africa. Proceedings of the 2nd International Workshop, Ouagadougou, 23-28 November 2003, pp. 63-84 [ID Brouwer, AS Traoré and S Trèche, editors]. http://www.mpl.ird.fr/ fn2ouaga/P2IW_Ouaga_A4.pdf

11. Gortmaker SL, Must A \& Perrin JM (1993) Social and economic consequences of overweight in adolescence and adulthood. N Engl J Med 329, 1008-1012.

12. Oguntona CRB \& Kanye O (1995) Contribution of street foods to nutrient intakes by Nigerian adolescents. Nutr Health 10, $165-171$.

13. World Health Organization (1995) Physical Status: the Use and Interpretation of Anthropometry. WHO Technical Report Series no. 854. Geneva: WHO

14. Cole TJ, Bellizzi MC, Flegal KM, et al. (2000) Establishing a standard definition for child overweight and obesity worldwide: international survey. BMJ 320, 1240-1243.

15. Cole TJ, Flegal KM, Nicholls D, et al. (2007) Body mass index cut offs to define thinness in children and adolescents: international survey. BMJ 335, 194.

16. Neovius M (2005) BMI, waist-circumference and waist-hipratio as diagnostic tests for fatness in adolescents. Int $J$ Obes 29, $163-169$.

17. Taylor RW, Jones IE, Williams SM, et al. (2000) Evaluation of waist circumference, waist-to-hip ratio, and the conicity index as screening tools for high trunk fat mass, as measured by dual-energy X-ray absorptiometry, in children aged 3-19y. Am J Clin Nutr 72, 490-495.

18. Food and Agriculture Organization (1997) Street Foods. FAO Food and Nutrition Paper no. 63. Rome: FAO.

19. Gibson R \& Ferguson E (1999) An Interactive 24-hour Recall for Assessing the Adequacy of Iron and Zinc Intakes in Developing Countries. Washington: ILSI Press.

20. Barikmo I, Ouattara F \& Oshaug A (2004) Food Composition Table for Mali. Oslo: Akershus University College.

21. West CE, Pepping F \& Temalilwa CR (1988) The Composition of Foods Commonly Eaten in East Africa. Wageningen, The Netherlands: Wageningen University for CTA and ECSA.

22. Wu Leung WT, Busson F \& Jardin C (1968) Food Composition Table for Use in Africa. Rome: FAO.

23. Mitchikpè CE (2007) Towards a Food-Based Approach to Improve Iron and Zinc Status of Rural Beninese Children: Enhancing Mineral Bioavailability from Sorghum-Based Food. Wageningen, The Netherlands: Wageningen University.

24. Arvaniti F \& Panagiotakos DB (2008) Healthy indexes in public health practice and research: a review. Crit Rev Food Sci Nutr 48, 317-327.
25. Burns C, Jackson M, Gibbons C, et al. (2002) Foods prepared outside the home: association with selected nutrients and body mass index in adult Australians. Public Health Nutr 5, $441-448$.

26. World Health Organization (2003) Diet, Nutrition and the Prevention of Chronic Diseases. Joint WHO/FAO Expert Consultation. WHO Technical Report Series no. 916. Geneva: WHO.

27. Nhung BT, Khan NC, Hop LT, et al. (2007) Resting metabolic rate of Vietnamese adolescents. Eur J Clin Nutr 61, $1075-1080$.

28. Wong W, Butte N, Hergenroeder A, et al. (1996) Are basal metabolic rate prediction equations appropriate for female children and adolescents? J Appl Physiol 81, 2407-2414.

29. Food and Agriculture Organization, World Health Organization \& United Nations University (1985) Energy and Protein Requirements. Report of a Joint FAO/WHO/UNU Consultation. WHO Technical Report Series no. 724. Geneva: WHO.

30. Black AE, Coward WA, Cole TJ, et al. (1996) Human energy expenditure in affluent societies: analysis of 574 doubly-labelled water measurements. Eur J Clin Nutr 50, 72-92.

31. World Cancer Research Fund \& American Institute for Cancer Research (2007) Food, Nutrition, Physical Activity, and the Prevention of Cancer: a Global Perspective. Washington, DC: AICR.

32. Van't Riet H, Den Hartog AP \& Van Staveren WA (2002) Non-home prepared foods: contribution to energy and nutrient intake of consumers living in two low-income areas in Nairobi. Public Health Nutr 5, 515-522.

33. Adamson A, Rugg-Gunn A, Butler T, et al. (1996) The contribution of foods from outside the home to the nutrient intake of young adolescents. J Hum Nutr Diet 9, 55-68.

34. Gewa C, Murphy S \& Neumann C (2007) Out-of-home food intake is often omitted from mothers' recalls of school children's intake in rural Kenya. J Nutr 137, 2154-2159.

35. Bere E, Veierbd M \& Klepp KI (2005) The Norwegian School Fruit Programme: evaluating paid vs. no-cost subscriptions. Prev Med 41, 463-470.

36. Bere E, Veierbd M, Bjelland M, et al. (2006) Free school fruit - sustained effect 1 year later. Health Educ Res 21, 268-275.

37. Bere E, Veierbd M, Skare O, et al. (2007) Free school fruit sustained effect three years later. Int J Behav Nutr Phys Act 4, 5.

38. Savy M, Martin-Prével Y, Sawadogo P, et al. (2005) Use of variety/diversity scores for diet quality measurement: relation with nutritional status of women in a rural area in Burkina Faso. Eur J Clin Nutr 59, 703-716.

39. Delisle H, Chandra-Mouli V \& De Benoist B (2001) Should Adolescents be Specifically Targeted for Nutrition in Developing Countries? To Address Which Problems, and How?. Geneva: WHO.

40. Katz D, O'Connell M, Njike V, et al. (2008) Strategies for the prevention and control of obesity in the school setting: systematic review and meta-analysis. Int $J$ Obes 32, $1780-1789$. 